\title{
Evolution of mitochondrial TAT translocases illustrates the loss of bacterial protein transport machines in mitochondria
}

\author{
Markéta Petrư ${ }^{1}$, Jeremy Wideman ${ }^{2,3}$, Kristoffer Moore $^{4}$, Felicity Alcock$^{5}$, Tracy Palmer $^{4}$ and Pavel Doležal ${ }^{1 *}$ (DD
}

\begin{abstract}
Background: Bacteria and mitochondria contain translocases that function to transport proteins across or insert proteins into their inner and outer membranes. Extant mitochondria retain some bacterial-derived translocases but have lost others. While BamA and YidC were integrated into general mitochondrial protein transport pathways (as Sam50 and Oxa1), the inner membrane TAT translocase, which uniquely transports folded proteins across the membrane, was retained sporadically across the eukaryote tree.

Results: We have identified mitochondrial TAT machinery in diverse eukaryotic lineages and define three different types of eukaryote-encoded TatABC-derived machineries (TatAC, TatBC and TatC-only). Here, we investigate TatAC and TatC-only machineries, which have not been studied previously. We show that mitochondria-encoded TatAC of the jakobid Andalucia godoyi represent the minimal functional pathway capable of substituting for the Escherichia coli TatABC complex and can transport at least one substrate. However, selected TatC-only machineries, from multiple eukaryotic lineages, were not capable of supporting the translocation of this substrate across the bacterial membrane. Despite the multiple losses of the TatC gene from the mitochondrial genome, the gene was never transferred to the cell nucleus. Although the major constraint preventing nuclear transfer of mitochondrial TatC is likely its high hydrophobicity, we show that in chloroplasts, such transfer of TatC was made possible due to modifications of the first transmembrane domain.

Conclusions: At its origin, mitochondria inherited three inner membrane translocases Sec, TAT and Oxa1 (YidC) from its bacterial ancestor. Our work shows for the first time that mitochondrial TAT has likely retained its unique function of transporting folded proteins at least in those few eukaryotes with TatA and TatC subunits encoded in the mitochondrial genome. However, mitochondria, in contrast to chloroplasts, abandoned the machinery multiple times in evolution. The overall lower hydrophobicity of the Oxa1 protein was likely the main reason why this translocase was nearly universally retained in mitochondrial biogenesis pathways.
\end{abstract}

Keywords: Mitochondrial evolution, TAT translocase, Protein transport, Hydrophobicity

\section{Introduction}

Mitochondria evolved from a single alphaproteobacterial ancestor [1]. The transformation of the endosymbiont into an organelle involved the redesign of its membranes and the loss of much of its original genetic information $[2,3]$. A key step in this transformation was the evolution of the protein transport machinery that allowed host proteins to be integrated into the evolving

\footnotetext{
*Correspondence: pavel.dolezal@natur.cuni.cz

'Department of Parasitology, Faculty of Science, BIOCEV, Charles University,

Průmyslová 595, 25250 Vestec, Czech Republic

Full list of author information is available at the end of the article
}

organelle. The evolution of these protein import pathways was a complex process, some pathways arose as eukaryotic novelties, whereas some were cobbled together using ancestral bacterial protein transport pathways [4].

Bacteria contain three translocases that function to transport distinct subsets of proteins across or into the inner membrane (IM). In bacteria, SecYEG is the main translocase that post-translationally [5] or co-translationally [6] transports unfolded polypeptides. YidC assists SecYEG in the assembly of membrane proteins or functions as the insertase on its own [7]. The twin-arginine translocase

(c) The Author(s). 2018 Open Access This article is distributed under the terms of the Creative Commons Attribution 4.0 International License (http://creativecommons.org/licenses/by/4.0/), which permits unrestricted use, distribution, and reproduction in any medium, provided you give appropriate credit to the original author(s) and the source, provide a link to the Creative Commons license, and indicate if changes were made. The Creative Commons Public Domain Dedication waiver (http://creativecommons.org/publicdomain/zero/1.0/) applies to the data made available in this article, unless otherwise stated. 
(TAT) allows transport of fully folded or even multi-subunit complexes across the inner membrane, which participate in diverse cellular processes such as respiration, photosynthesis and cell division [8].

In eukaryotes, while the function of the YidC homologue (Oxa1) is conserved, the function of SecY and TAT homologues is less clear. Unlike SecY and TAT, Oxa1 has a highly conserved primary structure and is encoded in the nuclear genome of all eukaryotes retaining a mitochondrial genome. It functions by mediating the co-translational insertion of membrane proteins translated on the mitochondrial ribosome [9]. The evolutionary path and the function of mitochondrial $(\mathrm{mt})$ TAT and Sec still remain largely unknown [10]. So far, mitochondrial SecY has been identified only in the mt genome of jakobids [11-13]. Conversely, although patchily distributed, TAT subunits have been found in the mt genomes of multiple eukaryotes ranging from jakobids to plants and even animals (i.e. sponges) [13-15]. The broad evolutionary distribution of TAT in eukaryotes implies functional significance, yet, protein transport by mitochondrial Tat translocase has not been investigated.

In bacteria, the TAT machinery is built from two types of proteins. Polytopic TatC comprising six transmembrane domains (TMDs) is the largest TAT protein and serves as the main component of the docking complex [16-19]. Different bacterial species contain between one and three paralogous TatA-type proteins, called TatA, TatB and TatE, each of which has an N-terminal TMD and a C-terminal helical domain exposed to the cytoplasm $[8,20]$.

Protein translocation in proteobacteria requires TatA, TatB and TatC and is initiated by the interaction of cargo signal peptide with the docking complex composed of TatB and TatC. This step is followed by TatC-mediated insertion of the signal peptide into the membrane [21] and subsequent oligomerisation of TatA subunits, which are assumed to form a transient translocation pore around the substrate [22]. In some species, the additional TatE subunit may play an analogous role to TatA, although it is not required for the normal function of the translocase [23]. The minimal functional TAT translocase in some Gram-positive bacteria and Archaea consists only of TatA and TatC subunits [24]. The TatA in these organisms is thought to fulfil the roles of both proteobacterial TatA and TatB proteins.

Eukaryotes are also known to contain TAT components. These proteins are always associated with mitochondria or plastids, the organelles of bacterial ancestry. While the TAT translocase was initially characterised in chloroplast thylakoids and has been studied in further detail $[25,26]$, only a single study on the mitochondrial TAT translocase has been published so far [14].
Here, we investigate the evolution and function of mitochondrial TAT translocases. By mapping the distribution of mitochondrial TAT subunits in eukaryotes we define three types of TAT-derived machineries with different constituent components (TatAC, TatBC and TatC-only). Using the TatAC machinery of the jakobid Andalucia godoyi, we demonstrate partial complementation of Escherichia coli TAT. The most common type of eukaryotic TAT is defined by the presence of only mitochondrially encoded TatC. We show that the TatC-only machinery from the heterolobosean Naegleria gruberi cannot complement E. coli TAT. In vivo, the protein forms stable high molecular weight complexes in the mitochondrial membrane. While TatC has been lost from the mitochondrial genome at least 21 times during the evolution of eukaryotes, we could not find any evidence for mitochondrial TatC in any nuclear genome. We discuss possible constraints of the gene transfer and propose a mechanistic solution, which has occurred for chloroplast TatC in the green plastid lineage.

\section{Results \\ Distribution of mitochondrial TAT in eukaryotes}

In order to gain a comprehensive picture of the distribution of the mitochondrial TAT pathway, available eukaryotic nuclear and mitochondrial genomes representing all major eukaryotic supergroups were searched for the presence of TatA-related and TatC proteins. TAT components could not be found in amoebozoans but could be found in all other major eukaryotic supergroups (opisthokonts, excavates, SAR and archaeplastids), plus cryptophytes and the newly identified protist Ancoracysta twista (Fig. 1a). In the vast majority of TAT-containing eukaryotic species, the presence of TAT machinery is limited to only TatC. TatA is only present in lineages that contain TatC, including jakobids [27], cryptists (including Palpitomonas bilix) [28], ochrophytes [29] and A. twista [30] (Fig. 1a).

In all cases, the mitochondrial Tat $\mathrm{A}$ and TatC components are encoded by the mitochondrial genome. However, the gene for a putative plant mitochondrial TatB was recently identified on the plant nuclear genome [14]. The product of this nucleus-encoded gene is localised to mitochondria and has been suggested to be part of a stable high molecular weight TatBC complex. The gene is slightly longer than its prokaryotic counterparts, and the role of the whole mitochondrial complex remains unknown. We searched the eukaryotic genomes for homologues of this mitochondrial TatB and identified several homologues in stramenopiles (like oomycetes) and cryptists (Fig. 1a), where it was also encoded in the nucleus. The eukaryotic and prokaryotic TatB proteins share a longer amphipathic $\alpha$-helix exposed to the cytoplasm/mitochondrial matrix when compared to 


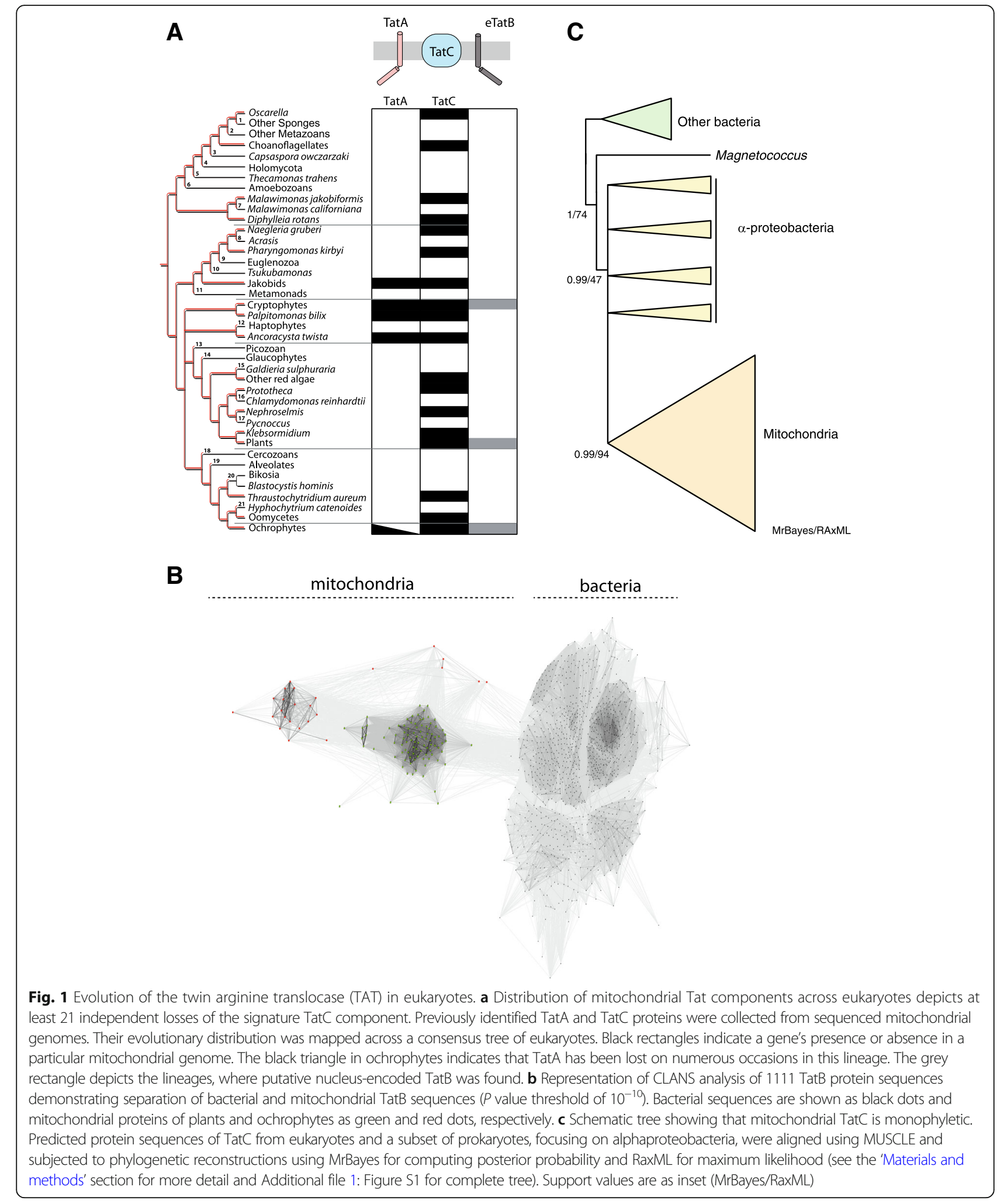

C

TatA proteins [31] and also conserved signature residues, including the essential glutamate residue in the TMD (Additional file 1: Figure S1). All of the TatB-positive eukaryotes carry mitochondrial encoded
TatC, which provides additional support for their possible function in mitochondria. However, we could not identify the common presence of all three mitochondrial TatABC subunits (Additional file 2: Table S1). 
A phylogenetic reconstruction of TatB proteins, which could resolve the origin of the eukaryotic proteins in different lineages of eukaryotes, was hampered by their very small size. Instead, a CLANS analysis, which is based on mutual blast comparisons, demonstrated that bacterial and (nucleus-encoded) mitochondrial TatB form distinct groups of sequences (Fig. 1b), suggesting that, although structurally related, no obvious horizontal gene transfer has occurred between these proteins. The analogous clustering analysis of bacterial and mitochondrial TatAs showed great divergence of the mitochondria-encoded proteins as they remained scattered without clear mutual affinity (Additional file 1: Figure S2). While parsimony would suggest that mitochondrial TatBs come from a common ancestral bacterial TAT, the reason why only TatBs and never TatAs are found in the nuclear genome remains a mystery.

The patchy distribution of mitochondrial TatC in eukaryotes indicates that the gene has been lost multiple times during evolution. To ensure that the patchy distribution is not seen due to repeat acquisition by lateral gene transfer (LGT) from bacteria, we reconstructed the phylogeny of TatC proteins from mitochondria and bacteria. A monophyletic mitochondrial TatC was recovered with high full support by both Bayesian (MrBayes) and maximum likelihood (RaxML) methods suggesting that mitochondrial TatC was derived from a single alphaproteobacterial origin, ruling out multiple LGTs from bacteria (Fig. 1c, Additional file 1: Figure S3). Mapping the presence and absence of TatC across a consensus tree of eukaryotes revealed that at least 21 losses occurred over the course of eukaryote evolution (Fig. 1a).

\section{Three arrangements of TAT-derived mitochondrial machinery}

The presence of TatABC components in almost all alphaproteobacteria [32] and the proposed origin of mitochondria within this group [33] indicate that the early mitochondrion also possessed a three-component translocase. Thus, since the TAT machinery is endosymbiont-derived, regardless of the distribution of TAT machinery, the last eukaryotic common ancestor (LECA) must have also contained a complete three-component translocase. We can conclude that the absence of any component must be due to loss.

Our comparative analysis suggests that evolution has generated different TAT-derived arrangements, which can be distinguished in extant mitochondria: (I) mitochondria-encoded TatA and TatC subunits reminiscent of the minimalist bacterial TAT translocase [24], (II) mitochondria-encoded TatC accompanied by nuclear-encoded TatB protein [14] and (III) mitochondria-encoded TatC-only systems. In regard to the non-uniform occurrence of mitochondrial Tat components, it seems very possible that a complete set of all three components will be identified when more nuclear genome sequences become available. Consequently, two independent questions have been raised: (1) has mitochondrial TAT retained its ancestral function in any of its derived forms? and (2) what is the current function of TAT in extant mitochondria?

\section{Andalucia godoyi TatAC complex retains ancestral functionality but TatC-only complex of $N$. gruberi and Malawimonas jakobiformis does not}

TatBC complexes have been recently investigated in plants, whereas the other two TatAC and TatC-only complexes have not yet been investigated [14]. Therefore, we sought to characterise the TatAC complex of Andalucia godoyi and the TatC-only complexes of Naegleria gruberi and Malawimonas jakobiformis.

A. godoyi is a deep-branching jakobid [34] with the greatest mitochondrial coding capacity known to date [13]. All jakobids are experimentally very challenging organisms, without any established biochemical, cell biological or molecular procedures. In order to test the function of $A$. godoyi and $N$. gruberi TAT machinery, we used a heterologous expression system in $E$. coli specifically engineered to characterise the function of the TAT translocase $[35,36]$. Briefly, the E. coli strains lacking all or a subset of tat gene(s) were transformed with plasmids carrying individual tat $A$ or tatC genes or a synthetic operon containing both $A$. godoyi genes. The functionality of the translocase was monitored by TAT-mediated translocation of AmiA, a cell wall hydrolase, the function of which is essential for the growth of the transformants on SDS-containing media [37]. Introduction of a synthetic operon of A. godoyi tat genes resulted in transport of AmiA carrying the signal peptide of SufI, another E. coli TAT substrate, as manifested by the restored growth of the strain on selective media (Fig. 2a). However, neither individual TatA nor TatC could complement the growth defect of the corresponding $E$. coli mutant strain when produced under natural (TAT) or strong (T7) promoters (Fig. 2b). These data strongly suggest that mitochondrial TAT proteins of $A$. godoyi represent functional machinery capable of substituting the role of the $E$. coli translocase.

The combination of mitochondrial and bacterial proteins did not result in a functional complex, likely due to the incompatible protein-protein interfaces. Negative results were also obtained using individual components of another jakobid Reclinomonas americana (Fig. 2b), further suggesting that mitochondrial and bacterial machineries are not compatible to combine into chimeric translocases.

Similarly, $\mathrm{NgTatC}$, representing the TatC-only system, was introduced into specific $E$. coli mutant strains 
A
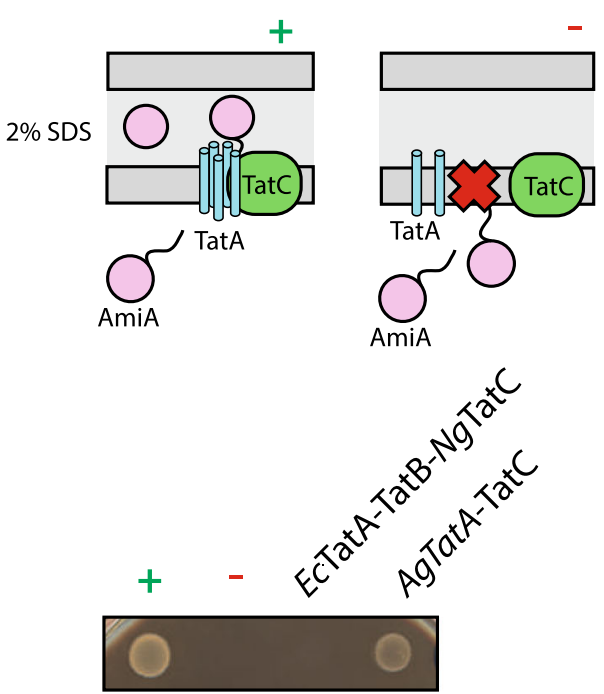

B

\begin{tabular}{|c|c|c|}
\hline & \multicolumn{2}{|c|}{$\Delta$ tat $A \Delta t a t E$} \\
\hline & tat & T7 \\
\hline RaTatA & - & - \\
\hline \multirow[t]{3}{*}{ AgTatA } & - & - \\
\hline & \multicolumn{2}{|c|}{$\Delta$ tatC } \\
\hline & tat & T7 \\
\hline AgTatC & - & - \\
\hline RaTatC & - & - \\
\hline MjTatC & - & \\
\hline NgTatC & - & - \\
\hline
\end{tabular}

\begin{tabular}{rcc} 
& \multicolumn{3}{r}{$\Delta \frac{\operatorname{tat} A B C \Delta t a t E}{\text { tat }}$} & T7 \\
NgTatC & - & - \\
MjTatC & - & -
\end{tabular}

C
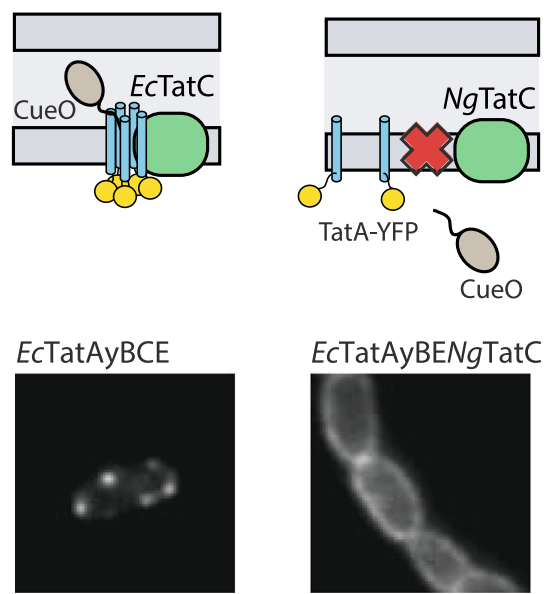

Fig. 2 Mitochondrial Tat proteins of A. godoyi but substitute for the function of E. coli TAT pathway. a Diagrams depict the principle of the complementation assay aimed at the translocation of TAT substrate (AmiA) across the inner E. coli membrane. + (pTAT101 plasmid carrying complete tat operon) and - (pTAT101 without tat operon) represent the positive and negative controls, respectively. In all strains (MCDSSAC $\Delta$ tat), mature domain of AmiA with Sufl Tat signal peptide was expressed. While A. godoyi mitochondrial TatA and TatC (expressed from pTAT101) could functionally replace $E$. coli proteins, $N$. gruberi TatC could not rescue the function when expressed in a synthetic operon with $E$. coli proteins. $\mathbf{b}$ Individual TatA and TatC were expressed from plasmids containing promotor of varying strength (tat or T7 promotor) in corresponding E. coli mutant (top line of each panel). None of the gene could functionally replace the bacterial protein or, in case of TatC, the whole TAT system. Ag-A. godoyi, $\mathrm{Ng}-\mathrm{N}$. gruberi, Ra-R. americana, Mj-M. jakobiformis. c Diagrams depict the clustering of YFP-tagged TatA (TatAy) induced upon the overexpression TAT substrate (CueO).

Replacing E. coli TatC with NgTatC abolished the formation of the active translocase clusters

lacking tatC gene or the whole tat operon. In these strains, the gene was expressed either alone or as a part of synthetic operon containing $E$. coli tat $A B$ genes. The premise for these combinations was that TatC-only system may carry out the role of full TAT translocase in mitochondria.

However, $\mathrm{NgTatC}$ was able to restore neither the function of TatC nor the complete TAT system in bacteria (Fig. 2b). To test whether another TatC-only system might restore the function of the E. coli mutant, analogous experiments were performed with TatC from Malawimonas jakobiformis. Similar to $N$. gruberi, $M$. jakobiformis also encodes only TatC (MjTatC) in the $\mathrm{mt}$ genome, but according to recent phylogenetic analyses $[38,39]$, it belongs to a different deep-branching clade of eukaryotes. Like the TatC from N. gruberi, MjTatC also failed to substitute for the E. coli protein in the AmiA translocation assay.

However, the expression of $M j \mathrm{TatC}$ in E. coli was not confirmed due to the lack of a protein tag or a specific antibody, as it was done for $N g$ TatC (see below). Given that both genes were similarly codon-optimised for the expression in E. coli, we assumed that, in both cases, the lack of complementation is caused by the inability of TatC to recognise a bacterial TAT substrate and trigger the translocation in concert with E. coli TatB and TatA proteins. Indeed, when $\mathrm{NgTatC}$ was expressed in place of the $E$. coli protein in bacteria carrying YFP-tagged TatA, no in vivo formation of transient TatA complexes was observed in contrast to the control cells, in which TatA complexes could be observed as fluorescent clusters (Fig. 2c). 
Naegleria gruberi TatC localises to mitochondria-enriched fraction in a high molecular weight complex

$\mathrm{NgTatC}$ is rather divergent compared to other mitochondrial (22\% identity to $A$. godoyi) and bacterial TatC proteins (14\% and $19 \%$ identity to E. coli and Aquifex aeolicus, respectively). This divergence could account for its inability to complement E. coli TAT. For instance, $\mathrm{NgTatC}$ and other heterolobosean proteins lack the key functional glutamate/glutamine residue (E170; E. coli numbering) of the central cavity, and the conserved phenylalanine residue (F94) involved in signal peptide binding was replaced by polar amino acid (Fig. 3a). In addition, a heterolobosean-specific insertion (of 22-23 AA) between the first and second transmembrane domains was detected (Fig. 3a). The overall divergence of the sequence is likely responsible for the relaxed predicted structure of $\mathrm{NgTatC}$, when compared to the TatC of $A$. aeolicus or the modelled structure of the A. godoyi protein (Fig. 3b).

In order to test whether $\mathrm{Ng}$ TatC is expressed and localised in mitochondria, a polyclonal antibody was raised against the very $\mathrm{C}$-terminus of the protein, which is predicted to be exposed to the mitochondrial matrix. Immunolabelling of the N. gruberi cellular fractions specifically detected a band of $35 \mathrm{kDa}$ in the cell lysate and mitochondria-enriched fraction, but not the cytosolic fraction. Hemerythrin- and alternative oxidase (AOX)-specific antibodies [40] were used to detect cytosolic and mitochondrial markers, respectively. Thus, we conclude that our antibody is detecting TatC in mitochondria (Fig. 3c).

The mitochondria-enriched fraction was further solubilised in digitonin and resolved on blue native (BN) PAGE. The western blot showed TatC to be present in a high molecular weight complex of approximately $900 \mathrm{kDa}$ (Fig. 3d), which was highly resistant to the increasing detergent concentration (0.5-2\%) and did not disassemble into smaller protein species. The mitochondrial TatC-containing complex in N. gruberi is larger than the bacterial or plastidial TatBC receptor complexes, which appear as a $440-$ or $700-\mathrm{kDa}$ complex on BN PAGE $[18,41]$, respectively. Within the bacterial and plastidial TatBC receptor complexes, TatB and TatC are of yet unspecified stoichiometry [42, 43], but both systems require the oligomerisation of TatC for proper function [44]. That $N g$ TatC is prone to oligomerise was also demonstrated by the expression of the hemagglutinin (HA)-tagged protein in E. coli, where even a larger complex was detected on BN-PAGE (Fig. 3d). Similarly, the plant mitochondrial TatBC-containing complex was also shown to migrate as a very large complex of $1500 \mathrm{kDa}$ [14], suggesting that TAT translocases in bacteria and plastids as well as mitochondrial TAT-derived machineries may be of different architecture.

\section{Search for the mitochondrial TAT substrate}

The activity of mitochondrial TAT in $A$. godoyi prompted us to search for putative TAT substrates. With regard to the presumed topological conservation of the translocase in bacterial and mitochondrial membranes, a putative substrate of the mitochondrial TAT translocase would be recognised by the receptor complex in the mitochondrial matrix and translocated into the intermembrane space. Such substrate(s) could originate from two distinct groups of proteins: either from mitochondria-encoded proteins, which would present the twin arginine signal peptide after their translation on the mitoribosome, or from nucleus-encoded proteins targeted to the mitochondrial matrix, which would expose the signal peptide upon the removal of their mitochondria targeting sequence. We analysed all 72 proteins encoded by the $\mathrm{mt}$ genome of $A$. godoyi using the TatP prediction algorithm [45], but no clear candidate proteins could be detected. This finding was further supported by the comparisons of mitochondrial genomes carrying/lacking Tat components [33] with the assumption that putative substrate of the TAT pathway would co-occur with subunits of the translocase. The fact that no such gene could be identified indicates that the substrate of mitochondrial TAT may be among the nucleus-encoded mitochondrial proteins. The bioinformatic search for such proteins is currently hindered by the lack of complete annotated $A$. godoyi genome.

Recently, the Rieske protein has been suggested as a putative mitochondrial TAT substrate [15]. This iron-sulfur cluster-containing protein was identified as a substrate of the plastid and bacterial TAT translocase [46-48]. Through analysis of a set of Rieske proteins, which showed a direct positive correlation between the presence of a Tat component in the mitochondrial genome and a twin arginine motif in the Rieske proteins, it was hypothesised that the analogous function may be performed by the mitochondrial TAT [15]. However, in yeast and possibly in other opisthokonts, Bcs1 AAA-ATPase was shown to mediate the translocation of the Rieske protein [49].

To test the possible role of TAT in Rieske protein translocation, we made a synthetic construct carrying the N-terminal part of $A$. godoyi mitochondrial Rieske corresponding to its bacterial counterparts fused to mature AmiA. The premise was that A. godoyi TAT machinery may recognise the signal peptide of its natural substrate even in the heterologous system, which could be monitored by the translocation of AmiA during the growth assay.

While the presence of the chimeric protein supported the growth of bacteria, which indicated successful AmiA translocation, we found that the translocation was not dependent on the presence of TAT (Fig. 4a). The same 


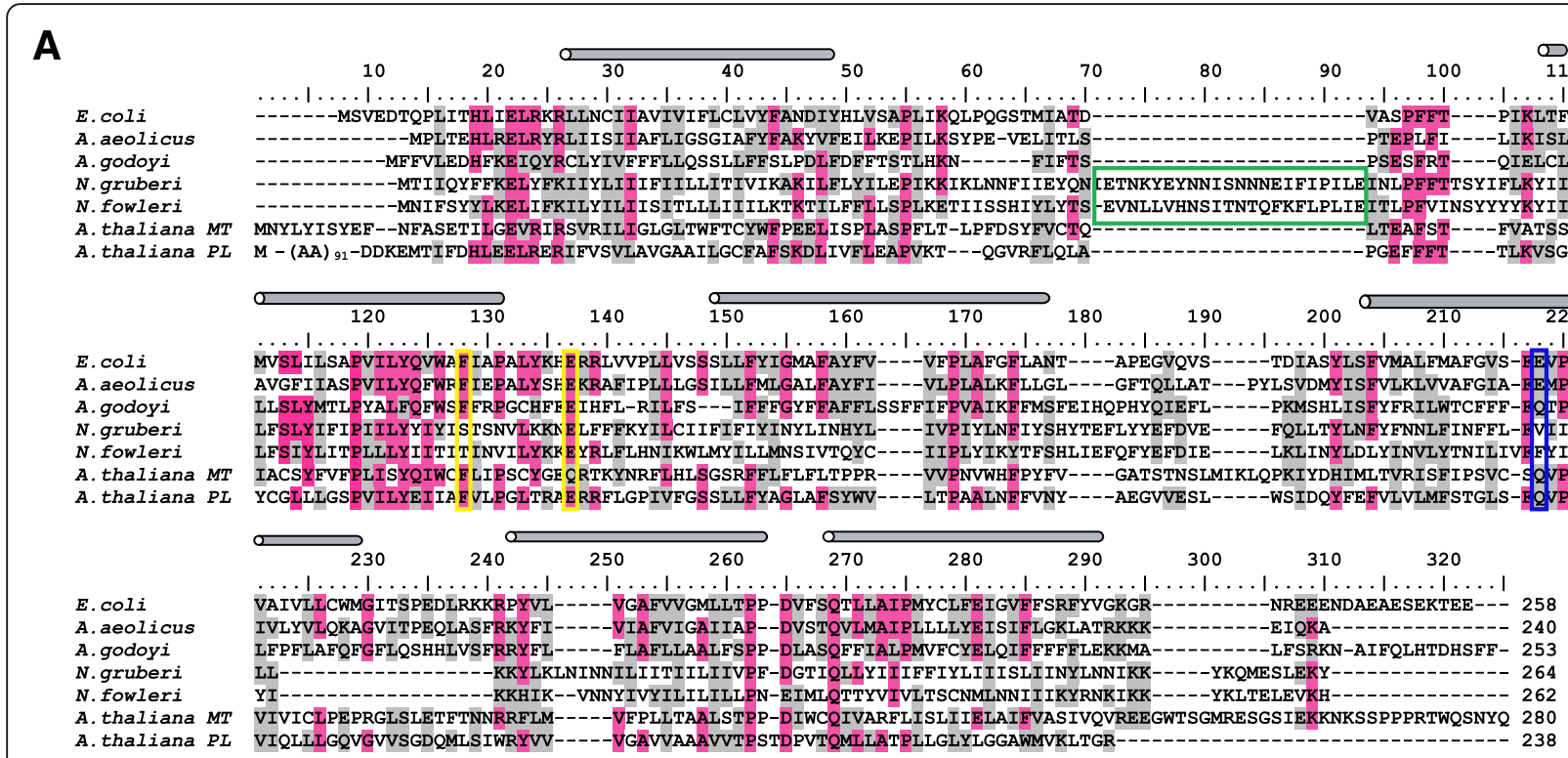

B

Aquifex aeolicus

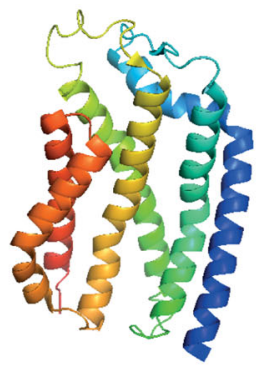

Andalucia godoyi

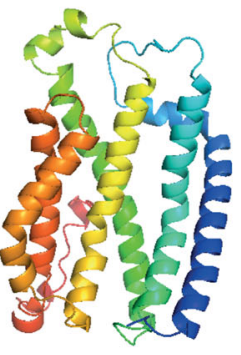

Naegleria gruberi

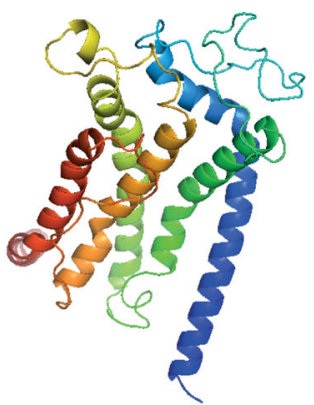

C

D
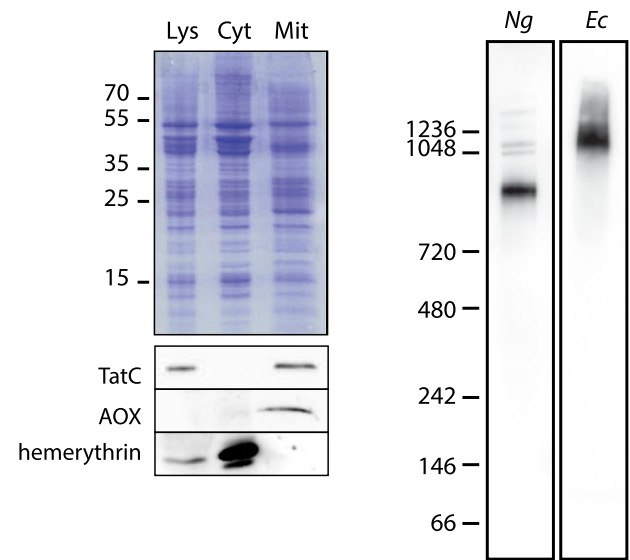

Fig. 3 Mitochondrial TatC of Naegleria gruberi. a Protein sequence alignment of bacterial and mitochondrial TatC proteins. The blue rectangle highlights the conserved glutamate/glutamine residue in the center of TatC cavity. The yellow rectangle depicts the position of conserved phenylalanine and glutamate residue of the signal peptide binding site. The green rectangle highlights the insertion common to heterolobosean TatC, and grey cylinders depict the transmembrane domains. Identical and similar residues are highlighted in pink and grey colour, respectively. The threshold for shading was 50\%. The C-terminal peptide used for antibody generation is underlined. $\mathbf{b}$ The comparison of structure of bacterial TatC protein from A. aeolicus [17] and TatC from A. godoyi and N. gruberi obtained by I-TASSER [69]. N. gruberi protein shows overall relaxed structure with unclear arrangement of the fifth membrane spanning domain $\mathbf{c}$ Western blot analyses of $\mathrm{N}$. gruberi cellular fractions. $\mathbf{d} \mathrm{NgTatC}$ forms high molecular weight complexes on BN-PAGE in mitochondria ( $\mathrm{Ng}$ ) and also when expressed with C-terminal HA-tag in E. coli (Ec). In both cases, the membranes were solubilised in $2 \%$ digitonin 
result was obtained when a chimeric construct based on the $N$. gruberi Rieske protein was co-produced in the presence of synthetic operon containing $\mathrm{NgTatC}$ (Fig. 4a).

We assumed that the designed hydrophobic synthetic signal peptide was recognised and translocated as Sec substrate instead of TAT pathway, as recently observed for mutant E. coli Tat signal peptide [50]. Such crosstalk between Sec and Tat pathways observed in bacteria did not allow us to test the actual interaction between mitochondrial Rieske and TAT pathway in bacteria. However, this situation cannot occur in the vast majority of mitochondria, as both mitochondrial Sec and Tat translocases have been found only in several jakobid species except $A$. godoyi $[11,13]$.

Comparison of the mitochondrial Rieske proteins confirmed the presence of twin arginine motif or its derived versions (RK, KR) at the conserved site [15]. It was demonstrated earlier that these imperfect motifs can be also transported via bacterial TAT [51]. However, the presence of these motifs does not correlate with the presence or the absence of Tat components in the mitochondria (Fig. 4b). It is thus possible that the same motif, which is used by the TAT pathway in bacteria may serve other purposes in mitochondria. The positively charged residues may perhaps rather define the positioning of the adjacent transmembrane anchor (Fig. 4b) of the Rieske protein in the inner mitochondrial membrane, instead of serving as a signal for TAT-dependent translocation.

To conclude, our experiments show for the first time that a mitochondrial-encoded TatAC complex constitutes a functional translocase. Nonetheless, the nature of the cargo transported out of mitochondrial matrix and perhaps into other cellular compartments of the eukaryotic cell remains unknown. Hence, future genomic and experimental analyses are necessary to understand the integration of different TAT-derived machineries into the mitochondrial protein transport pathways.

\section{The preservation or gradual loss of the inner membrane translocases of bacterial origin in eukaryotes}

As mentioned above, mitochondrial tatC and tatA genes could only be identified in the mitochondrial genome and not in the cell nucleus. This means the loss of tat $A$ and $t a t C$ genes from the mt genome was never accompanied by their transfer to the nuclear genome. Several different hypotheses explain the preservation of particular genes in mitochondrial genomes [33, 52, 53]. Among them, high hydrophobicity has been considered as one of the key pressures against the transfer of mitochondrially encoded genes to the nucleus.

The experimental allotopic expression of mitochondriaencoded proteins often results in protein degradation or mistargeting to other compartments [54, 55]. Surprisingly, when codon-optimised ngtat $C$ with a C-terminal GFP was expressed in Saccharomyces cerevisiae, the protein localised to mitochondria in some yeast cells even without an $\mathrm{N}$-terminal targeting sequence (Fig. 5a). However, the vast majority of cells $(\approx 95 \%)$ were devoid of any fluorescent signal, which likely indicated difficulty in handling such a hydrophobic protein. Similarly, $N g$ TatC without any tag was expressed in very low amounts in S. cerevisiae mitochondria (Additional file 1: Figure S4), making further characterisation of the protein (i.e. targeting, folding and topology) impossible.

In the context of mitochondrial gene transfer, the term 'hydrophobicity' can describe two different physical characteristics [55]: first, the overall hydrophobicity of the polypeptide, which can cause cytoplasmic aggregation if not bound by molecular chaperones [56], and second, the hydrophobicity of individual TMDs in the nascent polypeptide, which can be recognised by the SRP pathway [57] and incorrectly directed to the endoplasmic reticulum (ER) membrane.

In order to assess the actual hydrophobicity of mitochondrial TatC proteins, the grand average of hydropathy (GRAVY) was calculated. Mitochondrial TatC proteins were identified as highly hydrophobic proteins, greatly above the GRAVY values of typical polytopic inner mitochondrial membrane proteins like Tim23 and Oxal (Fig. 5b). Proteins as hydrophobic as mitochondrial TatCs would be expected to aggregate in the cytoplasm unless greatly assisted by molecular chaperones.

The propensity of a protein to be recognised by the SRP pathway in the cytoplasm and subsequently inserted into the ER membrane can be estimated by the procedure described by Björkholm et al. [58]. It takes into account free (membrane) insertion energy $(\Delta G, \mathrm{kcal} /$ $\mathrm{mol}$ ) of the first TMD appearing from the ribosome [59] and the presence of the following C-terminal part of the protein longer than 120 amino acid residues.

Plotting the calculated $\Delta G$ values of mitochondrial TatC TMDs suggests a strong tendency to be inserted into a membrane $(-\Delta G)$, which, together with a polypeptide length over 120 residues, strongly suggests that they would be preferentially recognised by SRP and mistargeting to the ER (Fig. 5c). Similarly, the known ancestral mitochondrial orthologues of the main bacterial $\mathrm{SecY}$ translocase, which were identified in the mitochondrial genome of jakobids, are highly hydrophobic protein, which would also be difficult to re-translocate into the organelle $[11,12]$.

\section{Discussion}

The adaptation of the endosymbiotic bacterium into the genetically dependent mitochondrion relied on reversing the protein flow across the symbiont's inner and outer 


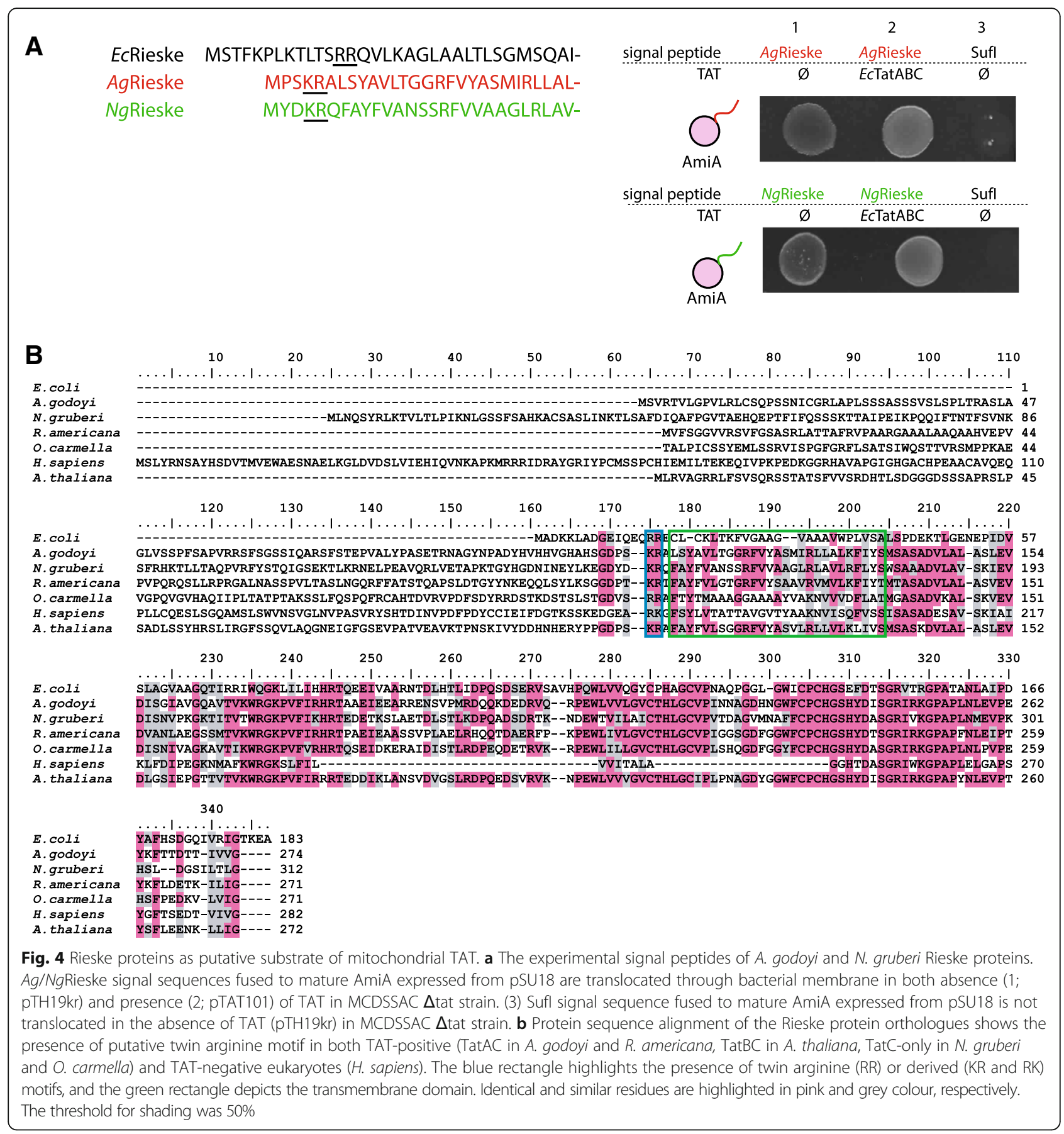

membranes. Multiple bacterial protein secretion pathways were replaced by mitochondrial protein import machines; however, a few have been retained by the organelle [4]. In addition to the orthologous core components of BAM and SAM complexes, which assemble the $\beta$-barrel proteins in the outer membrane of bacteria and mitochondria, respectively, orthologues of all three bacterial inner membrane translocases YidC/Oxa1, TAT and Sec can be found in mitochondria [13].
In comparison to TAT and Sec, both with highly limited distribution across eukaryotes, only Oxa1 has been maintained in the essential mitochondrial protein transport pathways [60]. However, given that diverse eukaryotes have retained functional TAT complexes in their mitochondria for over a billion years of evolution, evolutionary theory dictates that these translocases must be functionally important. Nonetheless, it is still unclear exactly what these functions are. 
A

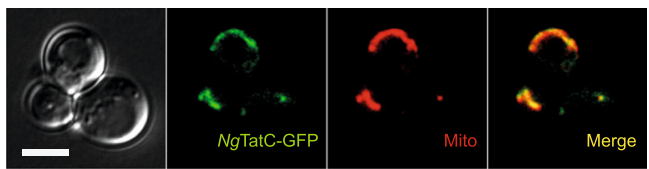

B

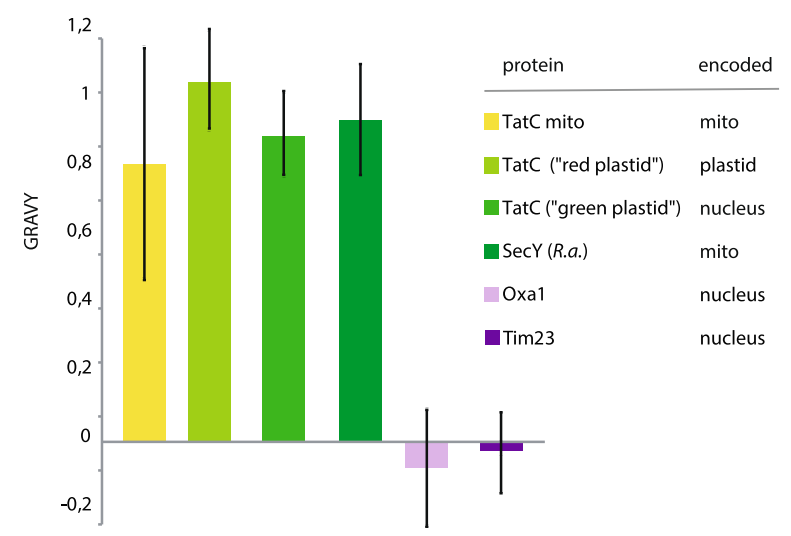

C

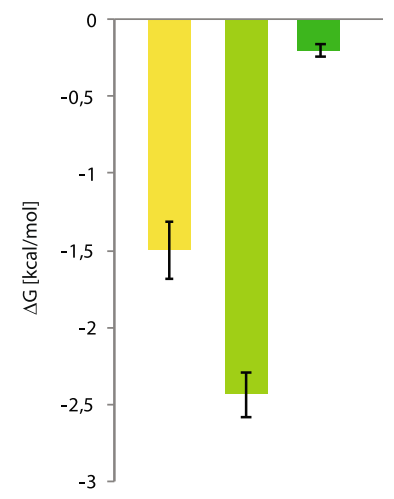

Fig. 5 Physical properties of mitochondria-encoded protein translocases. a Allotopic expression of NgTatC with the C-terminal GFP in S. cerevisiae. b The plot of GRAVY values of mitochondrial and plastid TatC proteins. c The plot of free membrane insertion energy $(\Delta G)$ of mitochondrial and plastid TatC proteins. The error bars represent standard deviation of the calculated values

While SecY and TatC are always encoded by the mitochondrial genome, Oxa1 is always encoded in the nucleus and posttranslationally translocated into mitochondria [60]. This means that while Oxa1 was able to be transferred to the nucleus and then retargeted to the mitochondria, SecY and TatC were never able to make that transition. Our comparison of Oxa1 to TatC and $\mathrm{SecY}$ suggests that it was the much lower hydrophobicity of the Oxal which enabled its nuclear transfer (Fig. 5b).

Interestingly, although mitochondrial TatC has never been transferred to the nucleus, chloroplast TatC has been successfully transferred in some lineages. Analyses of plastid TatC proteins showed that the proteins from both red and green plastids remained highly hydrophobic and in the case of red plastid TatC even exceeds the GRAVY values of mitochondrial proteins (Fig. 5b). However, according to free insertion energy $(\Delta G)$ calculations (Fig. 5c), the structure of the first TMD of green plastid TatC is much more favorable to escape SRP recognition, thus allowing the transport of TatC to the plastid.

The transfer of mitochondrial genes to the cell nucleus resulted in the formation of the eukaryote-specific protein import complexes in the inner mitochondrial membrane built around proteins from the Tim17 family [61]. That multiple eukaryotic lineages retained TatC in their mitochondrial genome without the pore-forming TatA subunit indicates a yet unknown mitochondria-specific adaptation of TAT and illustrates the gradual loss of its importance in mitochondrial biology. On the other hand, with the exception of the Rieske protein, there is currently no record of the export of proteins by any means across the inner mitochondrial membrane, which may indicate some yet unknown fundamental functional constrains linked to the process. In this context, Oxa1 in contrast to TAT and Sec translocases forms only an incomplete hydrophilic cavity and does not form a continuous channel across the membrane [62]. It is thus likely that the unique function of TAT, transporting even fully folded holoproteins, may thus not be compatible with the function of current mitochondria. For our future understanding of the actual function of mitochondrial TAT-derived machineries, the establishment of tractable genetic system in some of the diverse protist lineages is necessary.

\section{Conclusions}

The evolution of protein transport pathways in mitochondria has involved independent gains and losses of components of the inner and outer protein translocases. Here, we show that the TAT translocase of alphaproteobacterial ancestry has undergone a complex evolutionary history in eukaryotes. We demonstrate that the jakobid A. godoyi retains a functional TatAC complex capable of 
rescuing TAT-deficient $E$. coli, unlike the TatC-only complexes of $N$. gruberi and M. jakobiformis. Unfortunately, eukaryotic substrates stay elusive, and therefore, the function of all mitochondrial TAT complexes remains unknown. We suggest that the hydrophobicity of TatC made its transfer to the nuclear genome impossible. But why the complex is dispensable in so many eukaryotic lineages remains to be determined.

\section{Materials and methods}

\section{Bioinformatic analysis}

Homologues of TatA and TatC were identified in a subset of available mitochondrial genomes using a combination of BLASTp, tBLASTn [63], locally installed [64], and the online version of HMMer [65] and mfannot annotations (http://megasun.bch.umontreal.ca/ cgi-bin/mfannot/mfannotInterface.pl.) Initially, local HMMer search against 60 selected predicted eukaryotic proteomes (Additional file 2: Table S2), representing the major eukaryotic supergroups, was performed followed by the online search against UniProtKB. The Pfam seed alignments were used as a query.

In case of putative mitochondrial TatB proteins, HMMer search [65] (https://www.ebi.ac.uk/Tools/hmmer/) against UniProtKB was done using plant mitochondrial TatB as a query [14].

To reconstruct the phylogeny of tatC, protein sequences encoded in bacterial and mitochondrial genomes (165 sequences) were aligned using MUSCLE [66] and manually trimmed using Mesquite v2.75 resulting in 220 sites. Maximum likelihood bootstrap values (100 pseudoreplicates) were obtained using RAxML v8.2.10 [67] under the LG model [68] and MrBayes v.3.2.6 [69] for computation of posterior probabilities. MrBayes analyses were run with the following parameters: prset aamodelpr $=$ fixed $(\mathrm{LG})$, mcmcngen $=2,000,000$, samplefreq $=1000$, nchains $=4$, startingtree $=$ random and sumt burnin $=250$. Split frequencies and PRSF values were checked to ensure convergence (average SD of split frequencies $=0.035790$ ). The homology model of the three-dimensional structure of $\mathrm{NgTatC}$ and $\mathrm{AgTatC}$ was built with i-TASSER [70]. The GRAVY values were calculated by http://www.gravy-calculator.de/ and free (membrane) insertion energy $(\Delta G)$ by http://dgpred.cbr.su.se/ [59]. The transmembrane domains were predicted TMHMM [71]. Eukaryotic TatB secondary structures were modelled by MINNOU (http://minnou.cchmc.org/).

\section{Construct preparation}

AgTatA (YP_007890508.1), AgTatC (YP_007890501.1), MjTatC (NP_066348.1), NgTatC (NP_066540.1), RaTatA (NP_044807.1) and RaTatC (NP_044778.1) sequences were codon optimised for the expression in E. coli and synthesised (Thermo Fisher Scientific). For the complementation assays, tat $A$ and tat $C$ genes with the C-terminal His- or HA-tag on were cloned in pUNIPROM (tat promotor) within 5' BamHI and 3' XbaI cloning sites and pBluescript II KS+ (T7 promotor) within 5' ApaI and 3' SacI cloning sites (see Additional file 2: Table S3 for details on primers and restriction sites used). The synthetic TAT operon containing ngtatC (ectatA-tatB-ngtat $C$ ) or agtatAtat $C$ was synthesised and then cloned into pTAT101 within 5' BamHI and 3' PstI cloning sites. For TatA-YFP assay, ectat $B$ and ngtatC were amplified from ectatA-tatB-ngtatC synthetic operon and cloned into p101C*TatBC plasmid in place of ectat $B C$ within $5^{\prime}$ BamHI and 3' PstI cloning sites.

To test $A$. godoyi Rieske protein as a putative substrate of TAT, $A g$ Rieske coding sequence was recovered from the ongoing genome project (Marek Eliáš, unpublished). The sequence was codon optimised for the expression in E. coli and commercially synthesised (agrieskeopt).

For the generation of chimeric Rieske-AmiA constructs, putative mitochondrial targeting sequences of $A g$ Rieske (residues 2-79) and NgRieske (2-123) were removed and putative TAT signal sequences (residues 108-134 and 147-172, respectively) were added to mature E. coli AmiA. In both constructs, the cleavage site for bacterial signal peptidase was retained. The constructs were cloned into pSU18 within $5^{\prime}$ EcoRI and 3' XbaI cloning sites.

For the expression of ngtatCopt with the C-terminal GFP in S. cerevisiae, the gene was cloned into pUG35 within $5^{\prime} \mathrm{XbaI}$ and 3' BamHI cloning sites. For localisation of $N g$ TatC in yeast mitochondria, ngtatCopt was cloned into inducible vector pYES2.0 within $5^{\prime}$ BamHI and 3' Xhol cloning sites.

\section{N. gruberi cultivation and cell fractionation}

$N$. gruberi str. NEG-M was axenically cultured in M7 medium with penicillin $(10 \mathrm{U} / \mathrm{ml})$ and streptomycin $(10 \mu \mathrm{g} / \mathrm{ml})$ at $27{ }^{\circ} \mathrm{C}$ in vented tissue culture flasks. For cell fractionation, one $300-\mathrm{cm}^{2}$ cultivation flask with fully grown $N$. gruberi culture was harvested. Cells were collected by spinning at $1200 \times g / 10 \mathrm{~min} / 4{ }^{\circ} \mathrm{C}$. Pellet was washed once in cold $1 \times$ PBS and spun down. Cells were resuspended in $2 \mathrm{ml}$ of SM buffer $(250 \mathrm{mM}$ sucrose, $20 \mathrm{mM}$ MOPS pH 7.4) supplemented with Roche cOmplete $^{\mathrm{Tx}}$-EDTA-free Protease Inhibitor Cocktail and sonicated $3 \times 15 \mathrm{~s}(1 \mathrm{~s} / 1 \mathrm{~s}), 30 \%$. Resulting cell homogenate was then centrifuged at $1500 \times g / 10 \mathrm{~min} / 4{ }^{\circ} \mathrm{C}$ to remove unbroken cells and at 21,000 $\times g$ to obtain high-speed pellet corresponding to the mitochondria-enriched fraction. The resulting supernatant corresponded to the cytosolic fraction.

The expression of $N g$ TatC was verified by SDS-PAGE and western blot analysis using affinity-purified $\mathrm{Ng}$ TatC antibody raised against the C-terminal peptide 
(NIKKYKQMESLEKYC, unique to $N g$ TatC) obtained from Genscript. For Blue Native PAGE (BN-PAGE) analyses, the mitochondria-enriched fraction was solubilised in $0.5,1$ and $2 \%$ digitonin, and samples were resolved on $3-12 \%$ gel.

\section{E. coli cultivation and complementation assays}

Escherichia coli was cultivated aerobically in lysogeny broth (LB) or on LB agar. When required, antibiotics were used at the following final concentrations: ampicillin (amp) at $100 \mu \mathrm{g} / \mathrm{ml}$, kanamycin (kan) at $50 \mu \mathrm{g} / \mathrm{ml}$, chloramphenicol $(\mathrm{cml})$ at $50 \mu \mathrm{g} / \mathrm{ml}$ and apramycin (apra) at $50 \mu \mathrm{g} / \mathrm{ml}$. For complementation assays, LB agar with $2 \%$ SDS and particular antibiotic was used. Complementation assays were carried out as previously described [37, 72]. See Additional file 2: Tables S4 and S5 for details of E. coli plasmids and strains used in the study, respectively.

\section{Expression of TatC in S. cerevisiae and mitochondria isolation}

Saccharomyces cerevisiae str. YPH499 and INVSc1 was grown on YPD plates at $30{ }^{\circ} \mathrm{C}$ and after lithium-acetate transformation [73] on selective medium without uracil (SD-URA) at $30{ }^{\circ} \mathrm{C}$. For the fluorescence microscopy, $S$. cerevisiae str. YPH499 cells transformed with pUG35 carrying ngtatC were incubated with MitoTracker Red CMXRos $(1: 10,000)$ for 10 min, washed once in PBS and mounted in $2 \%$ low-melting agarose. Cells were viewed using an Olympus IX81 microscope and a Hamamatsu Orca-AG digital camera using the cell^ $\mathrm{R}$ imaging program at $\times 100$ magnification. For mitochondria isolation, S. cerevisiae str. INVSc1 transformed with pYES2.0 or pYES2.0 carrying ngtatC was harvested after induction of ngtatCopt expression on galactose selective medium without uracil [SC-URA(gal)]. The mitochondria were isolated as published previously [74]. Briefly, $250 \mathrm{ml}$ of the cells $\left(\mathrm{OD}_{600}=1\right)$ was collected by spinning at $5000 \times g / 5 \mathrm{~min} / 4{ }^{\circ} \mathrm{C}$. Pellet was washed once in $1 \times \mathrm{PBS}$ and spun down. Cells were resuspended in TRIS-DTT buffer $(0.1 \mathrm{M}$ Tris-SO4 pH 9.4; $10 \mathrm{mM}$ DTT) and incubated $15 \mathrm{~min} / 30{ }^{\circ} \mathrm{C}$ and, after, spun down at $5000 \times \mathrm{g} /$ $5 \mathrm{~min} / \mathrm{RT}$. Pellet was washed once in pre-warmed $1.2 \mathrm{M}$ sorbitol buffer (1.2 M sorbitol; $20 \mathrm{mM} \mathrm{KPi} \mathrm{pH} \mathrm{7.4)} \mathrm{and}$ spun down at $5000 \times g / 5 \mathrm{~min} / \mathrm{RT}$. $2.5 \mathrm{mg}$ zymolyase per gram of cells dissolved in pre-warmed $1.2 \mathrm{M}$ sorbitol buffer was added, and cells were incubated $30 \mathrm{~min} / 30{ }^{\circ} \mathrm{C}$ and then spun down at $5000 \times g / 5 \mathrm{~min} / 4{ }^{\circ} \mathrm{C}$. From here onwards, everything was kept at $4{ }^{\circ} \mathrm{C}$. Protoplasts were twice resuspended in cold $1.2 \mathrm{M}$ sorbitol buffer and spun down at $5000 \times g / 5 \mathrm{~min} / 4{ }^{\circ} \mathrm{C}$. Pellet was resuspended in $7 \mathrm{ml} \mathrm{BB6.0}$ buffer $(0.6 \mathrm{M}$ sorbitol; $20 \mathrm{mM} \mathrm{K}+\mathrm{MES} \mathrm{pH}$ 6.0) supplemented with Roche cOmplete ${ }^{\mathrm{rm}}$-EDTA-free Protease Inhibitor Cocktail and homogenised using a dounce. Homogenate was spun down at $5000 \times g / 5 \mathrm{~min} / 4{ }^{\circ} \mathrm{C}$ to get clean supernatant. Finally, the supernatant was spun at $13,000 \times g / 20 \mathrm{~min} / 4{ }^{\circ} \mathrm{C}$ to obtain high-speed pellet containing mitochondria.

\section{Additional files}

Additional file 1: Figure S1. Protein sequence alignment of eukaryotic TatB. Figure S2. CLANS analysis of TatA from bacteria and mitochondria. Figure S3. Phylogenetic reconstruction of bacterial and mitochondrial TatC. Figure S4. Expression of NgTatC in S. cerevisiae. (DOCX $1194 \mathrm{~kb}$ )

Additional file 2: Table S1. eTatB-positive species and the presence of mitochondria-encoded TatA and TatC. Table S2. Eukaryotic nuclear genomes used for the initial search of Tat components. Table S3. Primers used in the study. Table S4. Plasmids used in the study. Table S5. Bacterial strains used in the study. (XLSX $21 \mathrm{~kb}$ )

\section{Acknowledgements}

We would like to thank Ben Berks for his helpful comments and Marek Eliáš for providing us with the A. godoyi Rieske protein sequence.

\section{Funding}

This work was supported by Czech Science Foundation grant 13-29423S, the KONTAKT II grant LH15253 provided by Ministry of Education, Youth and Sports of CR and by the grant from Charles University Grant Agency no. 1215. This work was also supported by the Ministry of Education, Youth and Sports of CR (MEYS) within the National Sustainability Program II (Project BIOCEV-FAR, LQ1604) and the project 'Centre for research of pathogenicity and virulence of parasites' (No. CZ.02.1.01/0.0/0.0/16_019/0000759) funded by European Regional Development Fund (ERDF) and MEYS. JGW was supported by a College for Life Science Fellowship at the Wissenschaftskolleg zu Berlin.

\section{Availability of data and materials}

All data generated or analysed during this study are included in this published article and its additional files.

\section{Authors' contributions}

PD, MP, FA and TP designed the experiments. MP, FA and KM performed the experiments. MP, JW, FA, TP and PD analysed the data. MP, JW and PD wrote the manuscript. All authors read and approved the final manuscript.

Ethics approval and consent to participate

Not applicable

\section{Competing interests}

The authors declare that they have no competing interests.

\section{Publisher's Note}

Springer Nature remains neutral with regard to jurisdictional claims in published maps and institutional affiliations.

\section{Author details \\ ${ }^{1}$ Department of Parasitology, Faculty of Science, BIOCEV, Charles University, Průmyslová 595, 25250 Vestec, Czech Republic. ${ }^{2}$ Wissenschaftskolleg zu Berlin, Wallotstrasse 19, 14193 Berlin, Germany. ${ }^{3}$ Department of Biochemistry and Molecular Biology, Dalhousie University, PO Box 15000, Halifax, Nova Scotia B3H 4R2, Canada. ${ }^{4}$ Division of Molecular Microbiology, School of Life Sciences, University of Dundee, Dundee DD1 5EH, UK. ${ }^{5}$ Department of Biochemistry, University of Oxford, Oxford, UK.}

Received: 12 July 2018 Accepted: 1 November 2018 Published online: 22 November 2018

\section{References}

1. Gray MW, Burger G, Lang BF. Mitochondrial evolution. Science. 1999;283: 1476-81. 
2. Alcock F, Clements A, Webb C, Lithgow T. Tinkering inside the organelle. Science. 2010;327:649-50.

3. Gross J, Bhattacharya D. Mitochondrial and plastid evolution in eukaryotes: an outsiders' perspective. Nat Rev Genet. 2009;10:495-505.

4. Dolezal P, Likic V, Tachezy J, Lithgow T. Evolution of the molecular machines for protein import into mitochondria. Science. 2006;313:314-8.

5. Hartl FU, Lecker S, Schiebel E, Hendrick JP, Wickner W. The binding cascade of SecB to SecA to SecY/E mediates preprotein targeting to the E. coli plasma membrane. Cell. 1990;63:269-79.

6. Powers T, Walter P. Co-translational protein targeting catalyzed by the Escherichia coli signal recognition particle and its receptor. EMBO J. 1997;16:4880-6.

7. Wang P, Dalbey RE. Inserting membrane proteins: the YidC/Oxa1/Alb3 machinery in bacteria, mitochondria, and chloroplasts. Biochim Biophys Acta. 1808;2011:866-75.

8. Palmer T, Berks BC. The twin-arginine translocation (Tat) protein export pathway. Nat Rev Microbiol. 2012;10:483-96.

9. Ott M, Herrmann JM. Co-translational membrane insertion of mitochondrially encoded proteins. Biochim Biophys Acta. 1803;2010:767-75.

10. Gray MW, Lang BF, Burger G. Mitochondria of protists. Annu Rev Genet. 2004;38:477-524

11. Lang BF, Burger G, O'Kelly CJ, Cedergren R, Golding GB, Lemieux C, et al. An ancestral mitochondrial DNA resembling a eubacterial genome in miniature. Nature. 1997:387:493-7.

12. Tong J, Dolezal P, Selkrig J, Crawford S, Simpson AGB, Noinaj N, et al. Ancestral and derived protein import pathways in the mitochondrion of Reclinomonas america. Mol Biol Evol. 2011;28:1581-91.

13. Burger G, Gray MW, Forget L, Lang BF. Strikingly bacteria-like and gene-rich mitochondrial genomes throughout jakobid protists. Genome Biol Evol. 2013:5:418-38.

14. Carrie C, Weißenberger S, Soll J. Plant mitochondria contain the protein translocase subunits TatB and TatC. J Cell Sci. 2016;129:3935-47.

15. Pett W, Lavrov DV. The twin-arginine subunit C in Oscarella: origin, evolution, and potential functional significance. Integr Comp Biol. 2013;53: 495-502.

16. Blümmel A-S, Drepper F, Knapp B, Eimer E, Warscheid B, Müller M, et al. Structural features of the TatC membrane protein that determine docking and insertion of a twin-arginine signal peptide. J Biol Chem. 2017;292(52): 21320-9. https://doi.org/10.1074/jbc.M117.812560.

17. Rollauer SE, Tarry MJ, Graham JE, Jääskeläinen M, Jäger F, Johnson S, et al. Structure of the TatC core of the twin-arginine protein transport system. Nature. 2012;492:210-4.

18. Cline $\mathrm{K}$, Mori $\mathrm{H}$. Thylakoid DeltapH-dependent precursor proteins bind to a cpTatC-Hcf106 complex before Tha4-dependent transport. J Cell Biol. 2001; 154:719-29.

19. Alami M, Lüke I, Deitermann S, Eisner G, Koch H-G, Brunner J, et al. Differential interactions between a twin-arginine signal peptide and its translocase in Escherichia coli. Mol Cell. 2003;12:937-46.

20. Frobel J, Rose P, Muller M. Twin-arginine-dependent translocation of folded proteins. Philos Trans R Soc B Biol Sci. 2012;367:1029-46.

21. Fröbel J, Rose P, Lausberg F, Blümmel A-S, Freudl R, Müller M. Transmembrane insertion of twin-arginine signal peptides is driven by TatC and regulated by TatB. Nat Commun. 2012;3:1311.

22. Patel R, Smith SM, Robinson C. Protein transport by the bacterial Tat pathway. Biochim Biophys Acta. 1843;2014:1620-8.

23. Sargent F, Bogsch EG, Stanley NR, Wexler M, Robinson C, Berks BC, et al. Overlapping functions of components of a bacterial Sec-independent protein export pathway. EMBO J. 1998;17:3640-50.

24. Barnett JP, Eijlander RT, Kuipers OP, Robinson C. A minimal Tat system from a gram-positive organism: a bifunctional TatA subunit participates in discrete TatAC and TatA complexes. J Biol Chem. 2008;283:2534-42.

25. Cline K, Dabney-Smith C. Plastid protein import and sorting: different paths to the same compartments. Curr Opin Plant Biol. 2008;11:585-92.

26. Settles AM, Yonetani A, Baron A, Bush DR, Cline K, Martienssen R. Secindependent protein translocation by the maize Hcf106 protein. Science. 1997;278:1467-70

27. Jacob Y, Seif E, Paquet P-O, Lang BF. Loss of the mRNA-like region in mitochondrial tmRNAs of jakobids. RNA. 2004;10:605-14.

28. Nishimura Y, Tanifuji G, Kamikawa R, Yabuki A, Hashimoto T, Inagaki Y. Mitochondrial genome of Palpitomonas bilix : derived genome structure and ancestral system for cytochrome $\mathrm{c}$ maturation. Genome Biol Evol. 2016; 8:3090-8.
29. Ševčíková T, Klimeš V, Zbránková V, Strnad H, Hroudová M, Vlček Č, et al. A comparative analysis of mitochondrial genomes in eustigmatophyte algae. Genome Biol Evol. 2016;8:705-22.

30. Janouškovec J, Tikhonenkov DV, Burki F, Howe AT, Rohwer FL, Mylnikov AP, et al. A new lineage of eukaryotes illuminates early mitochondrial genome reduction. Curr Biol. 2017:27:3717-24 e5.

31. Hicks MG, de Leeuw E, Porcelli I, Buchanan G, Berks BC, Palmer T. The Escherichia coli twin-arginine translocase: conserved residues of TatA and TatB family components involved in protein transport. FEBS Lett. 2003;539:61-7.

32. Nuñez PA, Soria M, Farber MD. The twin-arginine translocation pathway in a-proteobacteria is functionally preserved irrespective of genomic and regulatory divergence. PLoS One. 2012;7:e33605.

33. Roger AJ, Muñoz-Gómez SA, Kamikawa R. The origin and diversification of mitochondria. Curr Biol. 2017;27:R1177-92.

34. Lara E, Chatzinotas A, Simpson AGB. Andalucia (n. gen.) - the deepest branch within Jakobids (Jakobida; Excavata), based on morphological and molecular study of a new flagellate from soil. J Eukaryot Microbiol. 2006;53:112-20.

35. Wexler M, Sargent F, Jack RL, Stanley NR, Bogsch EG, Robinson C, et al. TatD is a cytoplasmic protein with DNase activity. No requirement for TatD family proteins in sec-independent protein export. J Biol Chem. 2000;275:16717-22.

36. Keller R, de Keyzer J, Driessen AJM, Palmer T. Co-operation between different targeting pathways during integration of a membrane protein. J Cell Biol. 2012;199:303-15.

37. Ize B, Stanley NR, Buchanan G, Palmer T. Role of the Escherichia coli Tat pathway in outer membrane integrity. Mol Microbiol. 2003;48:1 183-93.

38. Derelle R, Torruella G, Klimeš V, Brinkmann H, Kim E, Vlček Č, et al. Bacterial proteins pinpoint a single eukaryotic root. Proc Natl Acad Sci U S A. 2015; 112:E693-9.

39. Heiss AA, Kolisko M, Ekelund F, Brown MW, Roger AJ, Simpson AGB. Combined morphological and phylogenomic re-examination of malawimonads, a critical taxon for inferring the evolutionary history of eukaryotes. R Soc Open Sci. 2018;5:171707.

40. Mach J, Bíla J, Žení̌́ková K, Arbon D, Malych R, Glavanakovová M, et al. Iron economy in Naegleria gruberi reflects its metabolic flexibility. Int J Parasitol. 2018:48:719-27.

41. Richter S, Brüser T. Targeting of unfolded PhoA to the TAT translocon of Escherichia coli. J Biol Chem. 2005;280:42723-30.

42. Alcock F, Stansfeld PJ, Basit H, Habersetzer J, Baker MA, Palmer T, et al. Assembling the Tat protein translocase. elife. 2016;5:13430-41.

43. Cline K. Mechanistic aspects of folded protein transport by the twin arginine translocase (Tat). J Biol Chem. 2015;290:16530-8.

44. Cléon F, Habersetzer J, Alcock F, Kneuper H, Stansfeld PJ, Basit H, et al. The TatC component of the twin-arginine protein translocase functions as an obligate oligomer. Mol Microbiol. 2015;98:111-29.

45. Bendtsen J, Nielsen H, Widdick D, Palmer T, Brunak S. Prediction of twinarginine signal peptides. BMC Bioinformatics. 2005;6:167.

46. Molik S, Karnauchov I, Weidlich C, Herrmann RG, Klösgen RB. The Rieske Fe/ $S$ protein of the cytochrome b6/f complex in chloroplasts: missing link in the evolution of protein transport pathways in chloroplasts? J Biol Chem. 2001;276:42761-6.

47. Bachmann J, Bauer B, Zwicker K, Ludwig B, Anderka O. The Rieske protein from Paracoccus denitrificans is inserted into the cytoplasmic membrane by the twin-arginine translocase. FEBS J. 2006;273:4817-30.

48. De Buck E, Vranckx L, Meyen E, Maes L, Vandersmissen L, Anné J, et al. The twin-arginine translocation pathway is necessary for correct membrane insertion of the Rieske Fe/S protein in Legionella pneumophila. FEBS Lett. 2007:581:259-64.

49. Wagener N, Ackermann M, Funes S, Neupert W. A pathway of protein translocation in mitochondria mediated by the AAA-ATPase Bcs1. Mol Cell. 2011:44:191-202.

50. Huang Q, Palmer T. Signal peptide hydrophobicity modulates interaction with the twin-arginine translocase. MBio. 2017:8:e00909-17.

51. Hinsley AP, Stanley NR, Palmer T, Berks BC. A naturally occurring bacterial Tat signal peptide lacking one of the "invariant" arginine residues of the consensus targeting motif. FEBS Lett. 2001;497:45-9.

52. Allen JF. Why chloroplasts and mitochondria retain their own genomes and genetic systems: colocation for redox regulation of gene expression. Proc Natl Acad Sci. 2015;112:10231-8.

53. Johnston IG, Williams BP. Evolutionary inference across eukaryotes identifies specific pressures favoring mitochondrial gene retention. Cell Syst. 2016;2: $101-11$. 
54. Perales-Clemente E, Fernández-Silva P, Acín-Pérez R, Pérez-Martos A, Enríquez JA. Allotopic expression of mitochondrial-encoded genes in mammals: achieved goal, undemonstrated mechanism or impossible task? Nucleic Acids Res. 2011;39:225-34.

55. Björkholm P, Ernst AM, Hagström E, Andersson SGE. Why mitochondria need a genome revisited. FEBS Lett. 2017;591:65-75.

56. Claros MG, Perea J, Shu Y, Samatey FA, Popot JL, Jacq C. Limitations to in vivo import of hydrophobic proteins into yeast mitochondria. The case of a cytoplasmically synthesized apocytochrome b. Eur J Biochem. 1995;228:76271.

57. von Heijne G. Why mitochondria need a genome. FEBS Lett. 1986;198:1-4.

58. Björkholm P, Harish A, Hagström E, Ernst AM, Andersson SGE. Mitochondrial genomes are retained by selective constraints on protein targeting. Proc Natl Acad Sci U S A. 2015;112:10154-61.

59. Hessa T, Meindl-Beinker NM, Bernsel A, Kim H, Sato Y, Lerch-Bader M, et al. Molecular code for transmembrane-helix recognition by the Sec61 translocon. Nature. 2007:450:1026-30.

60. Funes S, Kauff F, van der Sluis EO, Ott M, Herrmann JM. Evolution of YidC/ Oxa1/Alb3 insertases: three independent gene duplications followed by functional specialization in bacteria, mitochondria and chloroplasts. Biol Chem. 2011;392:13-9.

61. Žárský V, Doležal P. Evolution of the Tim17 protein family. Biol Direct. 2016; 11:54.

62. Hennon SW, Soman R, Zhu L, Dalbey RE. YidC/Alb3/Oxa1 family of insertases. J Biol Chem. 2015;290:14866-74.

63. Altschul SF, Madden TL, Schäffer AA, Zhang J, Zhang Z, Miller W, et al. Gapped BLAST and PSIBLAST: a new generation of protein database search programs. Nucleic Acids Res. 1997;25:3389-402.

64. Eddy SR. Accelerated profile HMM searches. PLoS Comput Biol. 2011;7: e1002195.

65. Finn RD, Clements J, Arndt W, Miller BL, Wheeler TJ, Schreiber F, et al, HMMER web server: 2015 update. Nucleic Acids Res. 2015;43:W30-8.

66. Edgar RC. MUSCLE: multiple sequence alignment with high accuracy and high throughput. Nucleic Acids Res. 2004;32:1792-7.

67. Stamatakis A. RAxML version 8: a tool for phylogenetic analysis and postanalysis of large phylogenies. Bioinformatics. 2014;30:1312-3.

68. Guindon S, Dufayard J-F, Lefort V, Anisimova M, Hordijk W, Gascuel O. New algorithms and methods to estimate maximum-likelihood phylogenies: assessing the performance of PhyML 3.0. Syst Biol. 2010;59:307-21.

69. Ronquist F, Huelsenbeck JP. MrBayes 3: Bayesian phylogenetic inference under mixed models. Bioinformatics. 2003;19:1572-4.

70. Yang J, Yan R, Roy A, Xu D, Poisson J, Zhang Y. The I-TASSER suite: protein structure and function prediction. Nat Methods. 2014;12:7-8.

71. Krogh A, Larsson B, von Heijne G, Sonnhammer EL. Predicting transmembrane protein topology with a hidden Markov model: application to complete genomes. J Mol Biol. 2001;305:567-80.

72. Alcock F, Damen MP, Levring J, Berks BC. In vivo experiments do not support the charge zipper model for Tat translocase assembly. elife. 2017;6. https://doi.org/10.7554/eLife.30127.

73. Gietz RD, Woods RA. Yeast transformation by the LiAc/SS carrier DNA/PEG method. In: Yeast protocols. New Jersey: Humana Press; 2006. p. 107-20.

74. Meisinger C, Pfanner N, Truscott KN. Isolation of yeast mitochondria. In: Yeast protocols. New Jersey: Humana Press; 2006. p. 033-40.

Ready to submit your research? Choose BMC and benefit from:

- fast, convenient online submission

- thorough peer review by experienced researchers in your field

- rapid publication on acceptance

- support for research data, including large and complex data types

- gold Open Access which fosters wider collaboration and increased citations

- maximum visibility for your research: over $100 \mathrm{M}$ website views per year

At BMC, research is always in progress.

Learn more biomedcentral.com/submissions 